\title{
Finding alternatives when a major database is gone*
}

\author{
Estelle Hu, MLIS, AHIP \\ See end of article for author's affiliation.
}

DOI: http://dx.doi.org/10.3163/1536-5050.104.2.011

Question: What to do when a major database ceases publication?

Setting: An urban, academic health sciences library with four campuses serves a university health sciences system, a college of medicine, and five other health sciences colleges.

Methods: Usage statistics of each e-book title in the resource were carefully analyzed. Purchase decisions were made based on the assessment of usage.

Results: Sustainable resources were acquired from other vendors, with perpetual access for library users.

Conclusion: This systematic process of finding alternative resources is an example of librarians' persistence in acquiring perpetual electronic resources when a major resource is cancelled.

Keywords: Databases, Library Collection Development, Textbooks as Topics, Statistics as Topic, Book Selection

Recent OCLC market research has found that ebooks are the number one priority in academic libraries in Germany, the Netherlands, the United Kingdom, and the United States [1]. Academic libraries have provided users with e-books for the convenience of access. This practice helps to save cost, especially for libraries with multiple campus locations. To provide electronic resources to patrons, libraries have to pay a substantial amount of money to maintain the resources from different packages offered by vendors. As the cost of subscription-based databases has increased every year and library budgets have been cut, librarians are facing challenges to provide resources to patrons with constrained budgets [2]. How will libraries ensure perpetual preservation of library collections with budget limitations [3]? Many of the databases that vendors offer are rental-based rather than ownership models. For rental models, libraries lose perpetual access to the electronic resources if they cannot renew the rental. In this scenario, librarians prefer to have perpetual ownership of electronic resources rather than leasing the resources from vendors [4].

\footnotetext{
${ }^{*}$ Based on a poster presentation at MLA '15, the 115th Annual Meeting of the Medical Library Association; Austin, TX; May 17-19, 2015.
}

Current and emerging trends raise questions about the extent to which academic research libraries should continue to seek perpetual access [5]. Libraries have no control over the models that vendors offer to customers; they must take whichever model is available that will meet their users' curricular or information needs. Once a rental subscription stops, libraries lose complete access to that resource.

The collections budget at the University of Illinois at Chicago (UIC) Library of the Health Sciences (LHS) has remained flat for several years. Because subscription fees increase annually, LHS librarians have been struggling to control escalating costs for the licensed resources to meet users' needs. This case study describes the development of a systematic process to find alternatives when an electronic resource is discontinued. This process took place from July to October 2014.

\section{CONTEXT}

LHS at UIC serves the Chicago campus, three other regional sites, and the University Hospital. All the sites have a College of Medicine and a College of 
Nursing. A public health program is available at the Chicago and Peoria campuses; a pharmacy program is at the Chicago and Rockford sites. Applied health sciences and dentistry programs are only available at the Chicago campus. LHS-Chicago is also the regional library of the National Network of Libraries of Medicine Greater Midwestern Region.

A major challenge to maintaining sustainable access occurred when a major electronic resource with different segments was to be discontinued by a publisher. Among the segments, an e-book collection was heavily used in the College of Medicine curriculum. Library liaisons, who were the first line of contact, informed each college that the resource would be discontinued by the end of December 2014 . LHS received comments and concerns from faculty over losing access to the e-books. With the discontinuation of this resource fast approaching, the author searched for alternatives to the e-book titles offered in this resource. After brainstorming with other librarians and liaisons for a solution, the author decided to develop a systematic process to pursue ebook collections from other avenues. The process was recorded in this case study to share this experience with colleagues who may deal with similar situations in the future.

\section{THE PROCESS}

The goal was to make sure that all the e-book titles from the discontinued database are available in the library collection so that users would have perpetual access without any interruption. To provide continuous access to the titles from the discontinued resource, the author began an analysis of the e-books available in this resource in July 2014. Fifty-eight titles were collected from the resource and saved in an Excel spreadsheet. Each title was checked in the library's open access public catalog (OPAC) to see if the e-book was available through a different vendor or if a print version of the e-book was available. At the same time, the author collected the usage statistics from the vendor for the period of January 2013 to July 2014. The usage had occurred within the 19-month period from all 4 LHS site locations, both on and off campus. The priority was to ensure continuous access to the most heavily used resources. The author identified the top 30 used titles to make purchase decisions. After careful study of the combined usage in 2013 and 2014, librarians decided to purchase titles with at least 2-seat licenses when the usage totaled more than 1,200 clicks.
Having users from 4 campus locations, the collections coordinator and the author thought 1,200 was a reasonable number to ensure extended access to the titles. Those titles with the highest usage would get 3-to-4-seat licenses to prevent turnaways. Titles of moderate usage, defined as between 500 to 1,200 clicks, would get a single-seat license. For the titles with less usage (less than 500) and for which the library did not have an electronic or print copy, a print copy would be acquired for the library collection.

The author explored the availability of these ebook titles in databases from different vendors. Two vendors with whom LHS had contracts were selected. Availability of each title was checked in each vendor's database. Both vendors provided single-user or multi-user license options. The library holdings, alternative e-book title availability, and price information were added to the spreadsheet along with the usage statistics. After collecting and recording all the needed information, the author was ready to purchase titles to ensure that there would not be any disruption when the resource ceased. Since UIC is a large urban university with more than 25,000 full-time equivalent (FTE) students and 4 site locations, the first vendor required LHS to purchase at least 2-seat licenses; additional seats would be purchased in multiples of 2. Four-seat licenses were bought for titles of higher usage (more than 2,500) to avoid turnaways. For the titles that could not be found with the first vendor, the e-books would be acquired from the second vendor. Any number of seat licenses could be purchased from the second vendor.

After the e-book titles were submitted for purchase and recorded on the spreadsheet, the author tracked the titles and made sure they were available to users. The author established a colorcoded system on the spreadsheet for ease of tracking the titles based on vendor, current e-book library holdings, number of seat licenses, availability in electronic or print format, print copies purchased, or nothing purchased. Once all the e-book titles were purchased, the author checked the remaining titles for availability in both vendors' databases. Some titles were not available in electronic format but were available in print. The author bought the print books to add to the library collection. In addition to a print copy, the author found topic-related e-book titles in the library OPAC and entered their links on the spreadsheet. The list was shared with liaisons, who added the links to subject guides in each discipline, providing users easy access to these resources. Some 


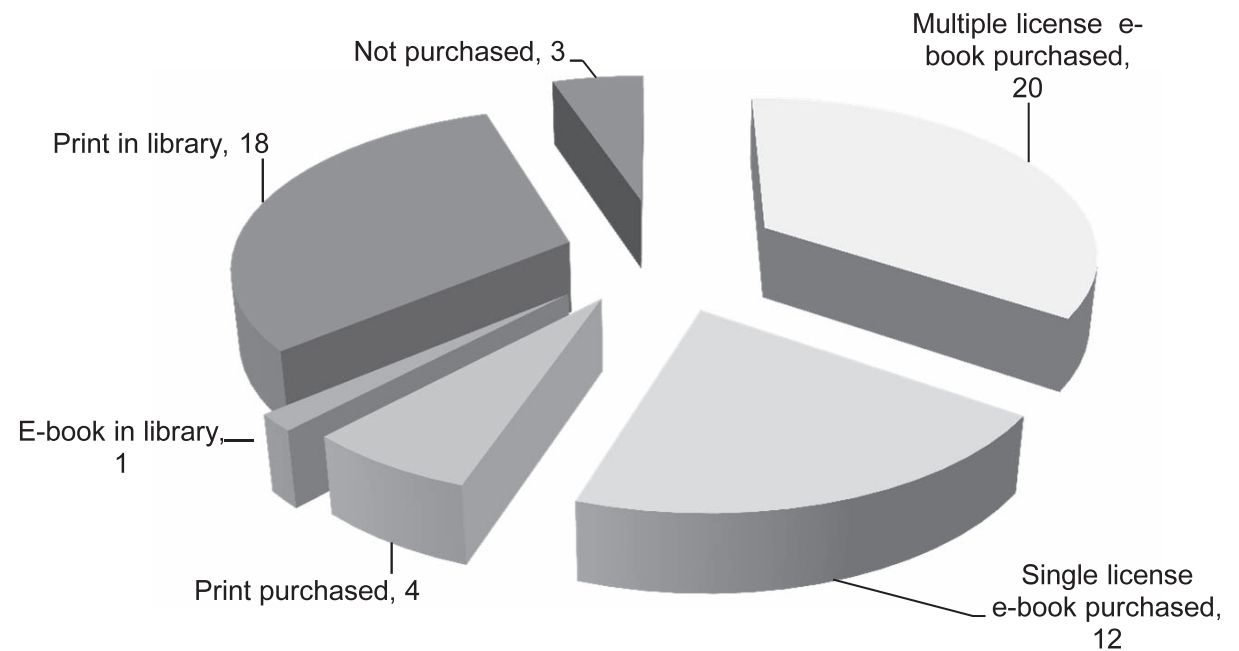

Figure 1

Outcomes of replacement

titles were available from both vendors in electronic format but only in a previous edition. For those titles, the author would continue to monitor the vendors' databases for availability of a new edition. The ebook titles would then be acquired and added to the library collection.

\section{OUTCOMES}

Based on the usage statistics, the top 30 of the 58 titles listed in 2013 and 2014 were identified and prioritized for purchase. Thirteen heavily used titles were already in library holdings, one in electronic format and the other 12 in print. Eighteen titles were purchased from the first vendor. Fifteen were purchased with 2-seat licenses and 3 with 4 -seat licenses. These 3 titles were on the top 10 of the list, and each one had more than 4,200 combined uses. Fourteen more titles were ordered from the second vendor. Two titles had 2-seat licenses purchased because the combined usage was more than 1,200. Twelve titles were purchased as e-books with a single license.

Overall, 20 titles were purchased with 2 or more seat licenses. Six out of the top 30 titles were not available from either vendor, including the most heavily used title, which had more than 29,000 combined uses. However, 3 or more print copies of this title were available at each of the 4 library locations. The author continued to monitor the 6 unavailable titles and hoped to acquire them in the future to meet users' needs. Because of their low usage, 4 print book titles were purchased even though e-books were available. The other 3 titles were not purchased because they did not fit into library collection criteria (Figure 1).

\section{DISCUSSION}

When LHS was ready to purchase the alternative ebook titles, the first vendor was running a promotion. The collections coordinator and the author ordered the e-book titles from the vendor, with a special discount on the total purchase, which resulted in a savings of about $\$ 14,000$. Awareness of vendors' promotions can help to decrease the library's expenditures, which is especially important in times of budget constraints.

Some platforms were more user friendly than others, and prices differed for each title by supplier. LHS could only purchase e-book titles from suppliers with whom the library had existing user license contracts. These factors affected purchase decisions. After the e-book titles were purchased, LHS negotiated with other suppliers to have additional contracts signed so that librarians could have more options in buying e-books from other suppliers in the future.

The author tracked the purchased e-book titles via the spreadsheet. Purchase confirmation and delivery were monitored, and access links were checked for validity. The author found that one of the eighteen titles ordered from the first vendor had been archived. The publisher released a newer edition of the e-book and withdrew the earlier edition from the 
first vendor. Once a title is archived, it is not available so the author purchased the e-book title from the second vendor.

Even though the 2014 usage was tallied for only 7 months, the usage numbers of 2 titles in 2014 were more than 400 times higher than the usage numbers in 2013. The author investigated this and found out that both titles were first published in 2014. Both titles might have been released at the end of 2013, and usage had accumulated since then, increasing in 2014. Both titles' usage numbers in 2014 were more than 1,100 , so the author decided to buy multiple licenses for these e-book titles. Some titles' usage numbers from 2013 were much higher than those of 2014 usage because those books were the textbooks for fall semester. These factors were weighed when making decisions on the number of licenses to purchase (Figure 1).

The process of identifying alternatives titles was facilitated by input from the library liaisons. Collection development is a collaborative process that helps libraries to build robust resources for library users. Library liaisons informed library users in each discipline that LHS had found alternatives for many titles from the cancelled resource. Links of topic-related e-books were shared with liaisons, who put the information on the library's research and subject guides to provide user access. Users sent comments to librarians expressing their satisfaction with continuous access to the book titles. The liaisons' close contact with and knowledge of their users' needs helped the author to make purchase decisions. Librarians working collaboratively helped to build consensus for collection development. The process of finding the alternatives is working well with the liaison model. For libraries that do not have a liaison model, librarians should consult with other departments or units for their needs and input to make purchase decisions.

Although the publisher provided a replacement database for the cancelled resource, it was too expensive for LHS to acquire at the time. Extra funds were made available later, and the replacement database was purchased. Future study will analyze the usage of these titles and those obtained from vendors that the author purchased to assess which of the access points patrons prefer for obtaining electronic resources.

This case study focused on the process of finding alternative resources when a resource is no longer available and the challenge to find suitable alternative e-book titles from other vendors. The above process worked out well for the library despite the limitations of time, budget, and resource availability. This process will be helpful to other librarians who may encounter similar situations in the future.

\section{ACKNOWLEDGMENTS}

The author thanks Maureen Clark for the initial input of the process and Rebecca Raszewski, AHIP, for reviewing and providing input on the case study.

\section{REFERENCES}

1. Dempsey L, Constance M, Brian L. Collection directions: the evolution of library collections and collecting portal. Libr Acad. 2014 Jul;14(3):393-423. 2. Guarria CI, Wang Z. The economic crisis and its effect on libraries. New Libr World. 2011 Jun;112(5/6):199-214. 3. Beebe L. Licensing electronic products at the American Psychological Association. Serials Libr. 2005 May;48(1): 175-84.

4. Glasser S. Providing perpetual access. Libr Resour Technical Serv. 2014 Jul;58(3):144-52.

5. Carr PL. The commitment to securing perpetual journal access: a survey of academic research libraries. Libr Resour Technical Serv. 2011 Jan;55(1):4-16.

\section{AUTHOR'S AFFILIATION}

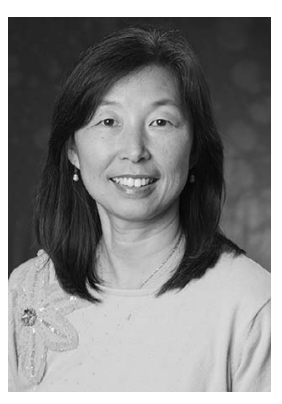

Estelle Hu, MLIS, AHIP, ehu@ uic.edu, Health Sciences Bibliographer and Assistant Professor, Library of the Health Sciences, University of Illinois at Chicago, 1750 West Polk Street, Chicago, IL 60612

Received August 2015; accepted November 2015 